\title{
Imaging and diagnostic approach of the adnexal mass: what the oncologist should know
}

\author{
Sara E. Vázquez-Manjarrez, O. Cristina Rico-Rodriguez, Nancy Guzman-Martinez, \\ Verónica Espinoza-Cruz, Denny Lara-Nuñez
}

Instituto Nacional de Ciencias Médicas y Nutrición Salvador Zubirán, Ciudad de México, México

Contributions: (I) Conception and design: SE Vázquez-Manjarrez; (II) Administrative support: Radiology Department; (III) Provision of study materials or patients: V Espinoza-Cruz; OC Rico-Rodriguez, SE Vázquez-Manjarrez; (IV) Collection and assembly of data: D Lara-Nuñez, OC Rico-Rodriguez, SE Vázquez-Manjarrez; (V) Data analysis and interpretation: D Lara-Nuñez, OC Rico-Rodriguez, SE Vázquez-Manjarrez; (VI) Manuscript writing: All authors; (VII) Final approval of manuscript: All authors.

Correspondence to: Sara E. Vázquez-Manjarrez, MD. Camino a Fuentes Brotantes 190 depto 601, Col. Santa Úrsula Xitla Tlalpan, 14420, Mexico City, Mexico. Email: docsaravazquez@gmail.com.

\begin{abstract}
Early detection and characterization of ovarian lesions is of utmost importance for adequate management. Ovarian cancer accounts for $3.3 \%$ of all cancers in women worldwide but has only a $5 \%$ of female cancer deaths because of low survival rates. The majority of ovarian lesions are benign and have spontaneous resolution. The adequate discrimination between benign and malignant lesions is the most important starting point for a correct and optimal management. Ultrasound is the method of choice up until now for adequate assessment of adnexal abnormalities, no other method has proven superior. Along time, there has been many classification systems that aim standardization of adnexal masses The Gynecology Imaging Reporting and Data System (GI-RADS), published in 2019. The International Ovarian Tumor Analysis (IOTA) group standardized in 2013 the approach of adnexal pathology descriptions by ultrasound with the limitation of needing pathologic reports for complete assessment. The Ovarian Adnexal Reporting and Data System (O-RADS) is a lexicon designed in 2018 to standardize definitions of characteristics by ultrasound. This system offers an interpretation method to decrease ambiguity and recommends management guides according to its classification.
\end{abstract}

Keywords: Adnexal mass; International Ovarian Tumor Analysis (IOTA); Ovarian Adnexal Reporting and Data System (O-RADS); ovarian cyst; ovarian cancer

Submitted Jan 21, 2020 Accepted for publication Aug 25, 2020.

doi: $10.21037 /$ cco-20-37

View this article at: http://dx.doi.org/10.21037/cco-20-37

\section{Introduction}

Early detection and characterization of ovarian lesions is of utmost importance for adequate management $(1,2)$. Ovarian cancer accounts for $3.3 \%$ of all cancers in women worldwide but has only a $5 \%$ of female cancer deaths because of low survival rates (1). Its late detection, due to the fact that early ovarian cancer is usually asymptomatic, causes advance disease and high mortality rates (3). The lifetime risk of having ovarian cancer accounts for $1.3 \%$ which is 1 in 78 women (2). In developed countries incidence of ovarian cancer is higher and represents the gynecological tumor with the greatest mortality rate (Table 1). Never the less, incidence has dropped overtime from a $29 \%$ documented in 2014 to a $6.6 \%$ in $2018(2,5)$. Higher risks of developing ovarian cancer are associated with menopausal hormone use (20\% higher), while using oral contraceptives, having a higher parity, tubal ligation and oophorectomy are associated with lower risks (3).

The majority of ovarian lesions are benign and have spontaneous resolution (4).

The adequate discrimination between benign and 
Table 1 Estimated incidence and mortality of ovarian cancer in 2018

\begin{tabular}{lcc}
\hline Region & Incidence $^{*}$ & Mortality $^{*}$ \\
\hline Worldwide & 295,414 & 184,799 \\
Asia & 153,076 & 92,257 \\
Europe & 67,771 & 44,576 \\
Africa & 27,194 & 16,702 \\
North America & 23,285 & 15,862 \\
Latin America and the Caribbean & 21,925 & 13,668 \\
Oceania & 2,163 & 1,464 \\
\hline
\end{tabular}

${ }^{*}$, number of cases. Source-reference (4).

Table 2 Evolution of adnexal mass classification systems throughout time

\begin{tabular}{ll}
\hline Period & Adnexal mass classification system \\
\hline 1993 & Kentucky Morphology Index \\
2000 & IOTA terms \\
2008 & IOTA simple rules \\
2010 & SRU \\
2011 & GI-RADS \\
$2014-2017$ & First international consensus on adnexal masses \\
$2015-2018$ & O-RADS US \\
$2015-2019$ & ADNEX model \\
2019 & SRU redefine simple cysts \\
2019 & Incidental findings CT \& MR for simple cysts \\
2019 & O-RADS MRI introduction (RSNA 2019) \\
\hline
\end{tabular}

Source-References (10-13).

malignant lesions is the most important starting point for a correct and optimal management (6). The goal of an early diagnosis is to reduce unnecessary surgical procedures and minimize unfavorable ovarian cancer outcomes. In contrast with other neoplasms, adnexal masses should not be biopsied, thus making imaging findings is crucial for diagnosis and management $(3,4)$.

Ultrasound is the method of choice up until now for adequate assessment of adnexal abnormalities, no other method has proven superior $(6,7)$ The American College of Radiology (8) classifies duplex ultrasound, ultrasound pelvis transvaginal and ultrasound pelvis transabdominal as usually appropriate for diagnosis of non-acute adnexal masses in all of its categories (9). When a cystic unilocular lesion is found, the risk of it evolving into malignancy is low, in premenopausal woman it represents less than $1 \%$ and $1.6 \%$ in postmenopausal women (9).

Along time, there has been many classification systems that aim standardization of adnexal masses (Table 2).

The Gynecology Imaging Reporting and Data System (GI-RADS), published in 2019, concluded that their classification system of diagnosis of adnexal masses by ultrasound has a high reliability with a sensitivity and specificity of $92.9 \%$ and $97.5 \%$ respectively (7). This classification also provides a risk of malignancy and is useful for clinical decisions (7).

The International Ovarian Tumor Analysis (IOTA) group standardized in 2013 the approach of adnexal pathology descriptions by ultrasound with the limitation of needing pathologic reports for complete assessment.

The Ovarian Adnexal Reporting and Data System (O-RADS) is a lexicon designed in 2018 to standardize definitions of characteristics by ultrasound. This system offers an interpretation method to decrease ambiguity and recommends management guides according to its classification $(1,14)$. The stage of ovarian cancer is given by International Federation of Gynecology and Obstetrics (FIGO), Tumor Node Metastasis (TNM) and American Joint Committee of Cancer (AJCC). In FIGO the most common stage of detection is FIGO III (3).

This review is not an encyclopedic review of adnexal masses and does not encompass every pathologic entity that may present and ovarian mass. It provides a practical introduction to the most recent classifications and imaging techniques for a correct approach of a suspected ovarian mass.

\section{Pathology}

Primary ovarian cancer can be classified as epithelial and non-epithelial with the first one being the most common. Nonepithelial neoplasms are less aggressive than epithelial ones. Usually epithelial tumors occur in patients older than 20 years and malignancy rates increase with age (3). The mature cystic teratoma is the most common benign ovarian tumor, usually occur in in younger women (3).

The World Health Organization Histological Classification (8) classifies ovarian cancer as surface epithelial (65\%), germ cell (15\%), sex cord-stromal (10\%), metastases $(5 \%)$ and other (10). Surface epithelial carcinomas are 
subclassified in serous (52\%), mucinous (6\%), endometroid $(10 \%)$ clear cell tumors $(6 \%)$ transitional cell tumor and epithelial-stromal tumors (10). Transitional cell tumors are divided in Brenner tumor, Brenner tumor of borderline malignancy, malignant Brenner tumor and Transitional cell carcinoma (non Brenner type). Epithelial- stromal tumors are divided in adenosarcoma and carcinosarcoma. The rest of the surface epithelial tumors are classified into benign, malignant and borderline $(2,3,10)$.

Sex cord-stromal tumors are subclassified into Granulosa tumors (fibromas fibrothecomas and thecomas), Sertoli Cell tumors (Leydig cell tumors), Sex cord with annular tubules, gynandroblastoma and steroid cell tumors $(2,10)$.

Germ cell tumors include teratomas (immature, mature, solid and cystic), monogermal, dysgerminoma, Yolk sac tumor and mixed germ cell tumors $(2,10)$.

Malignant or not otherwise specified tumors are metastatic lesions with a most frequent source coming from colonic, gastric or breast primary tumors $(3,10)$.

Although multiple screening trials for detecting early stage ovarian cancer in asymptomatic postmenopausal women have been conducted, to date none of them has shown benefit in terms of survival $(1,2)$. On the other hand, screening in high-risk groups is recommended (6).

The main objective of the evaluation of ovarian masses is the diagnosis or the exclusion of malignancy, to minimize unnecessary surgical procedures in benign lesions, and to optimize ovarian cancer outcomes by the opportune referral to a gynecologic oncologist in the malignant lesions $(2,3,11)$.

\section{Ultrasound}

Ultrasound is a fundamental tool in the assessment of adnexal lesions and along with clinic history and serum tumor markers (3), helps to triage women into risk management categories $(5,9,12)$. To date, ultrasound is the modality of choice for the initial approach of a suspected ovarian tumor.

Transvaginal ultrasound has a sensitivity of $90 \%$ and a specificity of $51-97 \%$ for detecting malignancy $(9,13)$. The degree of suspicion is based largely on the imaging features.

Ultrasound examination remains as the first-line imaging technique for the evaluation of ovarian disease $(13,15)$, it is cost effective, noninvasive, well-tolerated and widely available. In general, the use of transvaginal ultrasound is preferred over transabdominal ultrasound, but its limitations come with its limited field of view that may result in failure to entirely visualize the uterus, ovaries or masses lying
Table 3 IOTA simple descriptors

Benign descriptors
Unilocular tumor with ground-glass echogenicity in
premenopausal women
Unilocular tumor with mixed echogenicity and acoustic
shadows in premenopausal women
Unilocular anechoic tumors with regular walls and largest
diameter lesion of $<100$ mm
Unilocular tumor with regular walls
Malignant descriptors
Tumors with ascities, moderate Doppler bloodflow in
postmenopausal women. Women $>50$ y.o. CA-125 $>100 \mathrm{IU} / \mathrm{mL}$

higher in the pelvis; in these cases, the evaluation may be followed by a brief transabdominal ultrasound (15).

Mayor groups have developed imaging criteria and prediction models for characterization of adnexal masses: the IOTA, The Society of Radiologists in Ultrasound (16), the First International Consensus Report on Adnexal Masses and most recently O-RADS $(1,4)$, among others.

The largest diagnostic accuracy study regarding sonographic differentiation of the benign or malignant nature of and adnexal mass was the IOTA study $(17,18)$.

The IOTA group has proposed a three-step strategy to improve the adnexal mass assessment. First step is using Simple Descriptors by pattern recognition. Second step, IOTA Simples Rules and third step a subjective assessment of an expert radiologist. This method has been proven to be the one with the best sensibility and specificity to classify adnexal masses (19).

\section{IOTA “Simple Descriptors"}

Also known as easy instant diagnosis, consist of six specific ultrasonographic patterns that correspond to specific adnexal pathologies and measurements of serum CA-125 in 50-year old or older patients (see Table 3 and Figure 1) (19).

If none of them is applicable, the mass is considered as "non-classifiable" or "non-instant". Would lead to the second step: IOTA Simples Rules $(7,17)$ (Figure 2).

\section{IOTA "Simple Rules"}

The IOTA study, which began in 1999 , is the largest study in the literature for the sonographic diagnosis and 

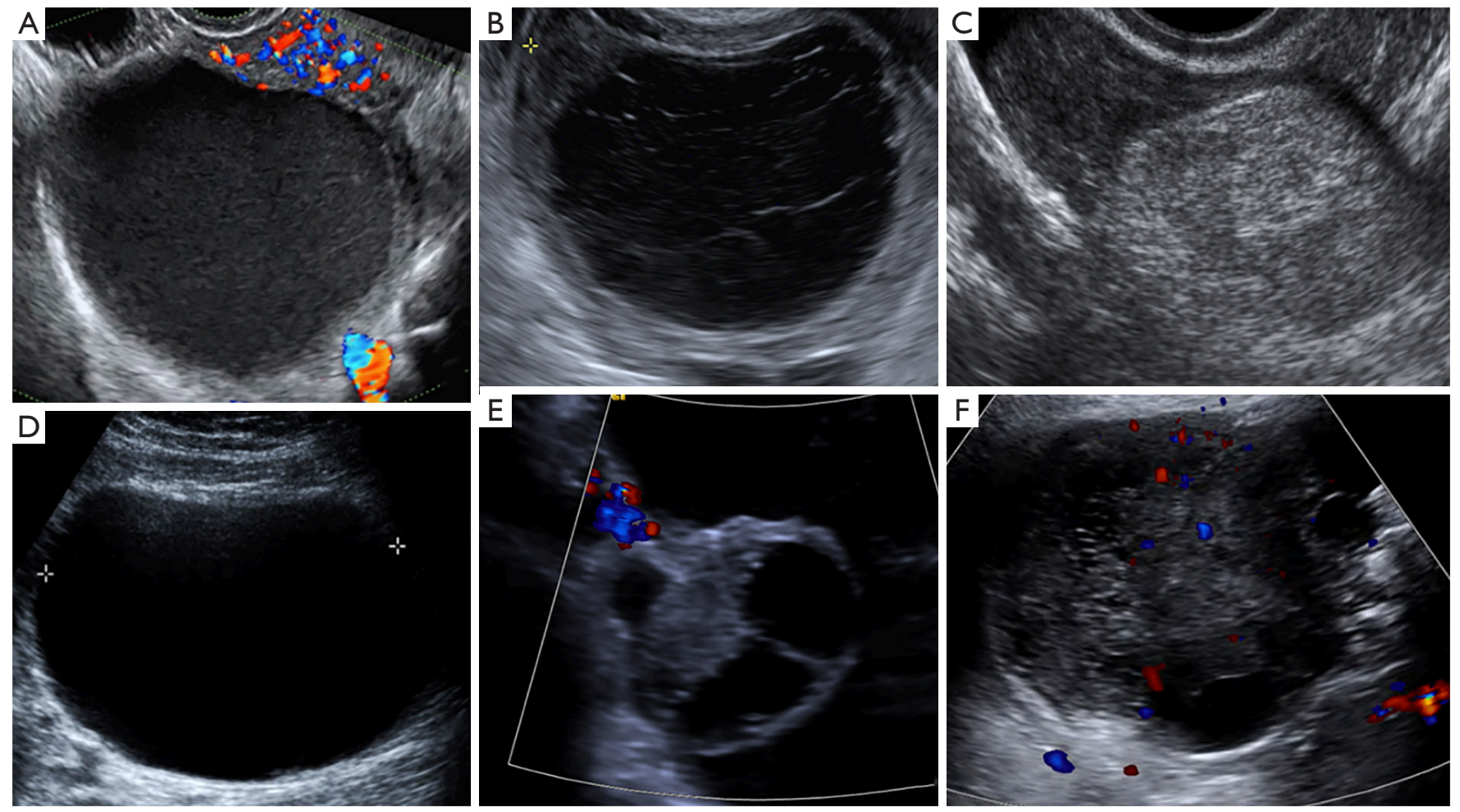

Figure 1 International Ovarian Tumor Analysis (IOTA) simple descriptor patterns. (A) BD unilocular tumor with ground-glass echogenicity consistent of endometrioma; (B) BD unilocular tumor with mixed echogenicity and acoustic shadows consistent with a hemorrhagic cyst; (C) BD unilocular tumor with regular walls consistent with a dermoid tumor; (D) BD unilocular anechoic adnexal mass with regular walls consistent with a functional cyst; (E) MD tumor with ascitis in a carcinosarcoma adnexal tumor; (F) solid tumor with moderate blood flow.

preoperative classification of ovarian masses.

The "Simple Rules" by IOTA study group were developed at 2008, they consist in a conjunct of five sonographic findings indicative of a benign lesion (B-features) and five sonographic findings indicative of a malignant lesion (M-features) (Tables 4,5, Figures 3-5).

According to this Simple Rules, an ovarian tumor is benign if only B-features are present and malignant if only $\mathrm{M}$-features are present. If both features apply, or no features are present, the lesion cannot be categorized.

The Simple Rules has a sensitivity of $91-96 \%$ and $68-93 \%$ of specificity when performed by inexperienced sonographers (20) diagnosing $75 \%$ of adnexal masses. The third step is for the left $25 \%$ inconclusive lesions, which is to refer the case to an expert sonographer or to a gynecology oncologist as $40 \%$ of the inconclusive cases would ultimately prove to be malignant (21).

Garg et al. published in 2017 the values of sensitivity and specificity previously mentioned, and an accuracy of $88 \%$ when the inconclusive cases were classified as malignant (20).

\section{The Society of Radiologist in Ultrasound (16) consensus [2019]}

In 2019, the Society of Radiologist in Ultrasound published its second systematic guideline consensus (first published in 2010) for the management of simple ovarian cysts. These guidelines were designed to be applied in asymptomatic patients and in patients with symptoms not attributable to the ovarian lesion, as a method to share expertise.

In recent studies, the low risk of malignancy of simple ovarian cysts has been demonstrated, irrespective of their size.

The majority of the small simple cyst do not need followup. If a cyst is not very-well characterized a second opinion ultrasound or follow-up is recommended, to warrant that a solid part is not being missed. It also helps to assess the rate growth of cysts (22). 

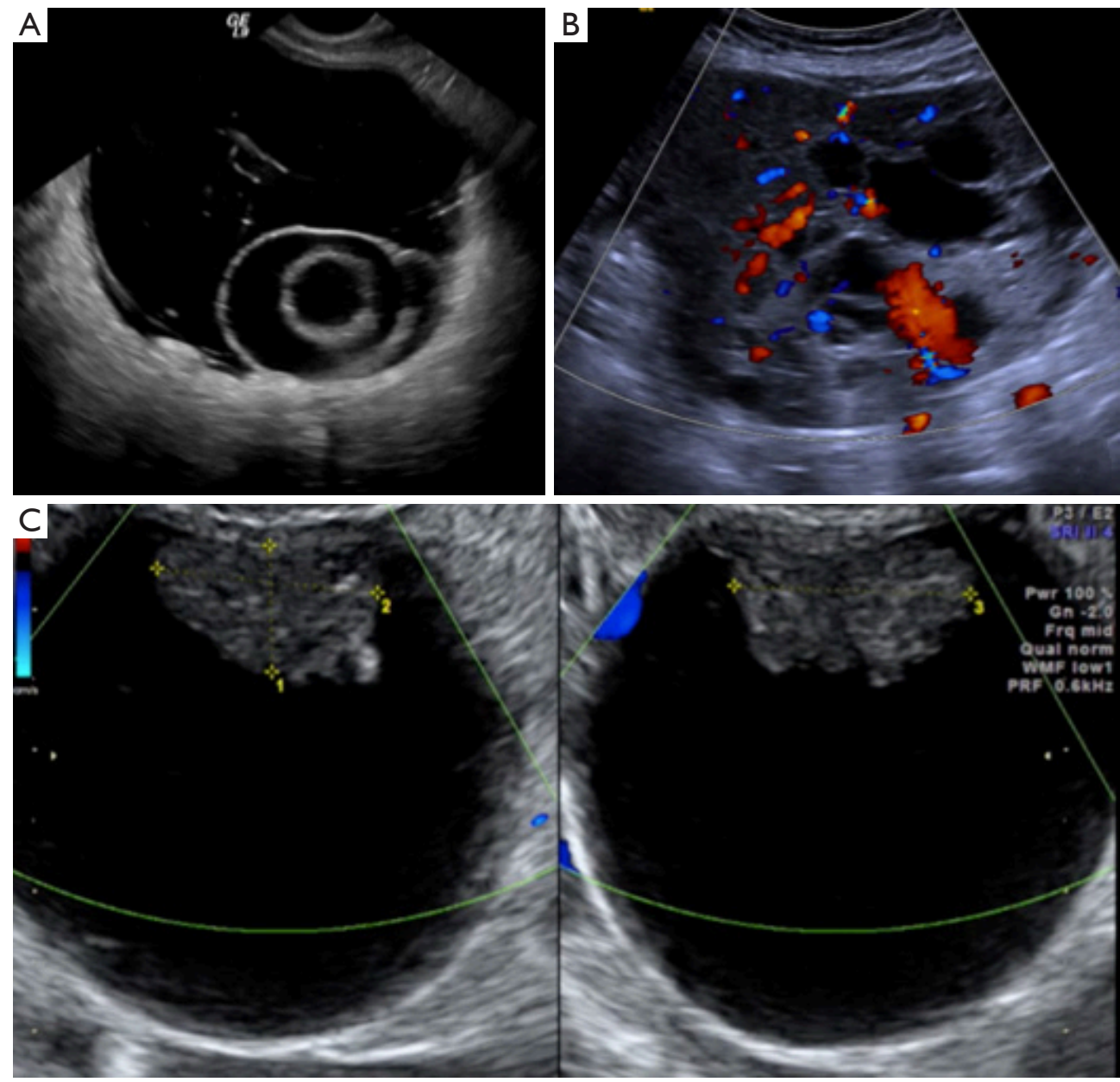

Figure 2 Transvaginal adnexal ultrasound of two patients classified after International Ovarian Tumor Analysis (IOTA) criteria. (A) Multilocular left ovarian tumor with less than $10 \mathrm{~cm}$ in diameter. Benign features: (B) solid and cystic adnexal mass, highly vascularized ovarian tumor. Malignant features: (C) cystic lesion with a solid papillary projection greater than $7 \mathrm{~mm}$. Indeterminate lesion.

A simple cyst must meet the following characteristics in order to be named as such: anechoic, with thin and smooth walls, unilocular, no internal Doppler flow and has to be entirely evaluated.

If there is doubt that a cyst is simple or not, it should be followed to assess growth, if it decreases in size and remains as a simple cyst, it is no longer necessary to follow it, due to its low possibility of malignancy. A follow-up two years later, will confirm this assertion.

If the simple cyst increased in size, then it is most likely a cystadenoma. It is suggested to follow it by ultrasound and clinically for two years to assess the growth rate.

The larger the cyst size, the greater the risk of missing solid parts. To date, there is no consensus for this size threshold, so the O-RADS size thresholds are currently used for the follow-up of cysts with suboptimal characterization (22) (Figures 6,7).

\section{First international consensus report on adnexal masses: management recommendations [2014-2017]}

It was the first collaborative international multidisciplinary consensus. They established that it was appropriate to use pattern recognition or algorithm approaches (simple rules at that time) and if the lesion is still indeterminate, proceed to the second steps: referral to expert sonographers, serial ultrasound, application of established risk models, referral to MRI o to gynecology oncologist management.

They also added the clarified that simple ovarian cysts are not precursors to malignant ovarian carcinoma and they 
Table 4 Five malignant features

\begin{tabular}{|c|c|c|}
\hline Abbreviation & Description & Example \\
\hline M1 & $\begin{array}{l}\text { Irregular solid } \\
\text { tumor }\end{array}$ & \\
\hline M2 & Presence of ascitis & \\
\hline M3 & $\begin{array}{l}\text { At least } 4 \text { papillary } \\
\text { structures }\end{array}$ & \\
\hline & $\begin{array}{l}\text { Irregular } \\
\text { multilocular solid } \\
\text { tumor with largest } \\
\text { diameter over } 10 \\
\mathrm{~cm}\end{array}$ & \\
\hline & $\begin{array}{l}\text { Very strong color } \\
\text { Flow (CS 4) }\end{array}$ & \\
\hline
\end{tabular}

raised the size threshold for follow-up simple cysts to $10 \mathrm{~cm}$.

\section{ADNEX model (IOTA group) 2015-current}

The ADNEX model is a risk prediction model than can distinguish between benign, borderline, stage I invasive, stage II-IV invasive, and secondary metastatic adnexal ovarian tumors. It is a risk prediction model that uses 9 predictors (Figure 8):

* Three clinical features: Oncologic vs nononcologic center, serum cancer antigen 125 (Ca-125) level and
Table 5 Benign features

\begin{tabular}{|c|c|c|}
\hline Abbreviation & Description & Example \\
\hline B1 & $\begin{array}{l}\text { Unilocular cyst in } \\
\text { any size }\end{array}$ & \\
\hline B2 & $\begin{array}{l}\text { Solid components } \\
\text { either not present } \\
\text { or less than } 7 \mathrm{~mm} \\
\text { in diameter }\end{array}$ & \\
\hline B3 & $\begin{array}{l}\text { Presence } \\
\text { of acoustic } \\
\text { shadowing }\end{array}$ & \\
\hline B4 & $\begin{array}{l}\text { Smooth } \\
\text { multilocular } \\
\text { tumor with largest } \\
\text { diameter less } \\
\text { than } 10 \mathrm{~cm}\end{array}$ & \\
\hline B5 & $\begin{array}{l}\text { No blood flow (CS } \\
\text { 1) }\end{array}$ & \\
\hline
\end{tabular}

the age of the patient;

- Six ultrasound predictors: maximum lesion diameter, maximum soft tissue diameter, $>10$ locules, number of papillary projections, acoustic shadowing, ascites (20).

\section{O-RADS}

O-RADS risk stratification and management system by the American College of Radiology (8) was created to unify interpretations and reduce ambiguity in the management 

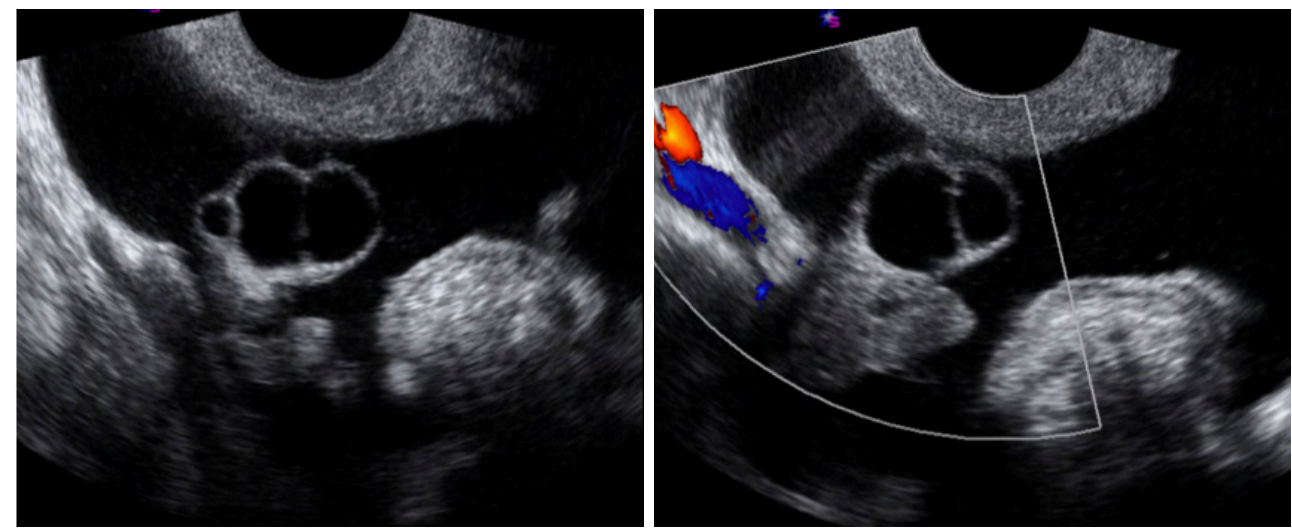

Figure 3 Smooth multilocular cyst, largest diameter $<10 \mathrm{~cm}$ (B4), with no internal flow (B5) or solid components. Ascites secondary to a condition unrelated to the ovaries.

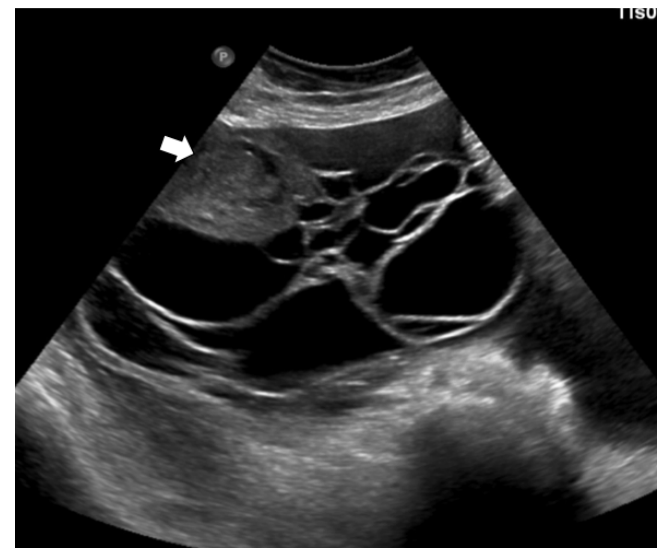

Figure 4 M4: irregular, multilocular solid (arrow) tumor with largest diameter $>10 \mathrm{~cm}$ in a cystadenocarcinoma.

and classification of adnexal masses.

This system includes the pattern-based approach and algorithm IOTA-ADNEX model system; it consists in a system of six categories (0 to 5). Each of these categories shows an estimated risk percentage of malignancy and provides management recommendations (follow-up, treatment, referral, etc.) for each risk group, divided into pre and postmenopausal patients, defining this last category as women with a year or more of amenorrhea (1).

\section{Considerations}

These recommendations have been published to guide management of women with low-average risk of ovarian cancer, who are asymptomatic and have an ovarian lesion.
These guidelines are not a rule, and cases should be individualized by professional judgement as needed.

The size of the ovarian lesion will be determined according to its largest diameter.

O-RADS applies only to lesions involving the ovaries or fallopian tube.

The recommendations given by O-RADS are based on transvaginal ultrasound, although they may be complemented by transabdominal ultrasound if needed (1).

The O-RADS categories are described next (Figure 9).

\section{Recommendations}

Until now, no system has been able to fully include all aspects of the management of ovarian lesions. The O-RADS ultrasound system attempts to unify, standardize and define more clearly when referring a patient, the follow-up and management, increasing the sensitivity (not the specificity) to reduce the amount of undiagnosed ovarian cancers, since it has a high mortality rate (1).

The largest diagnostic accuracy study regarding sonographic differentiation of benign and malignant adnexal masses was the IOTA study (17).

* RADS 0: incomplete evaluation, it may due to technical factors or inability to tolerate endovaginal imaging.

* RADS 1: normal premenopausal ovary (physiologic category). This category is important just in premenopausal women. It comprehends ovarian follicle and corpus luteum, and they should be described as so, rather than cysts.

- RADS 2: almost certainly benign $(<1 \%$ risk of 

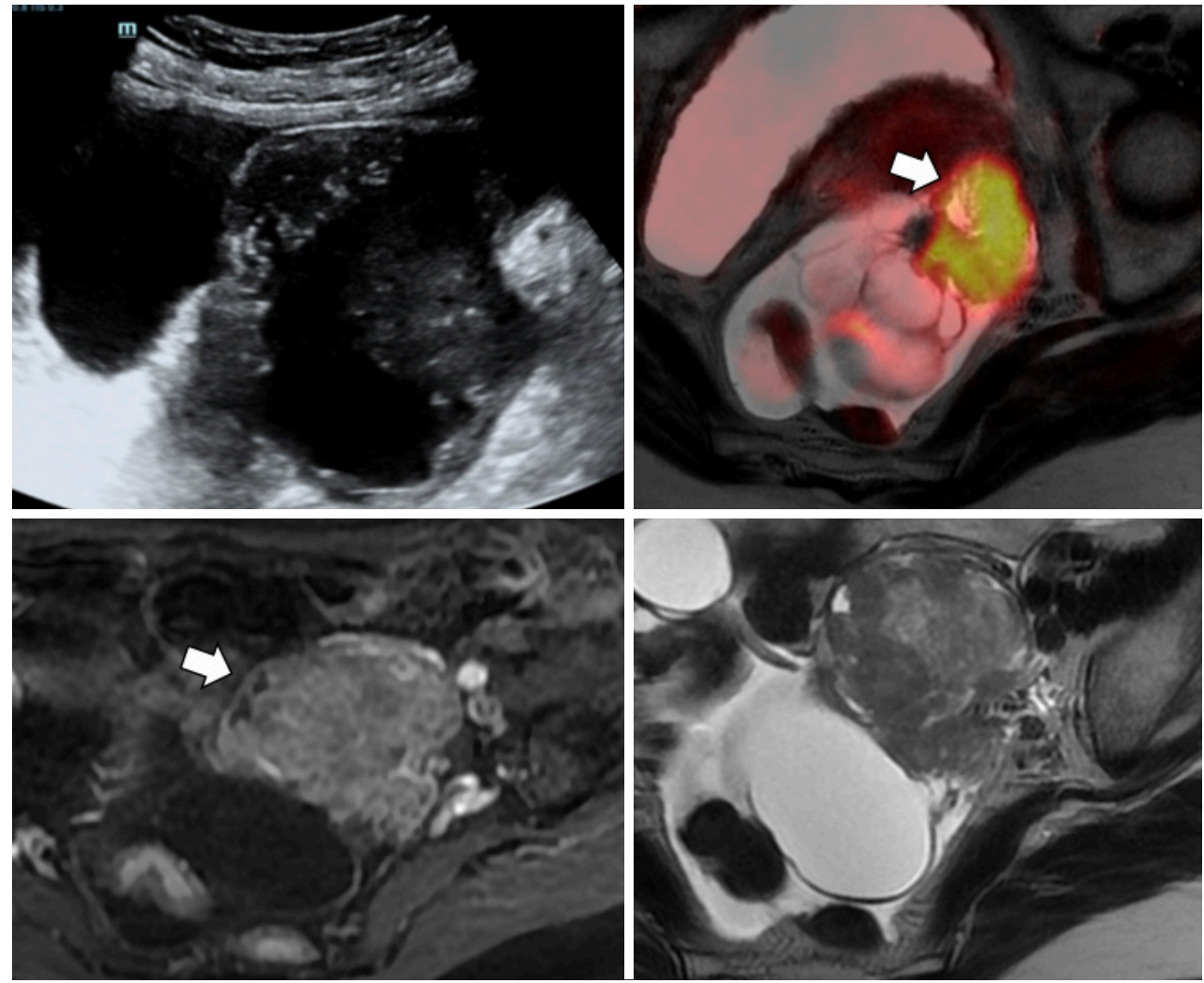

Figure 5 Irregular multilocular-solid tumor with largest diameter $>10 \mathrm{~cm}$ (M4). PET/MRI and MRI acquisitions show hypermetabolism and heterogeneous post-contrast enhancement in the solid portion of the lesion (arrow) corresponding to a high-grade serous carcinoma.

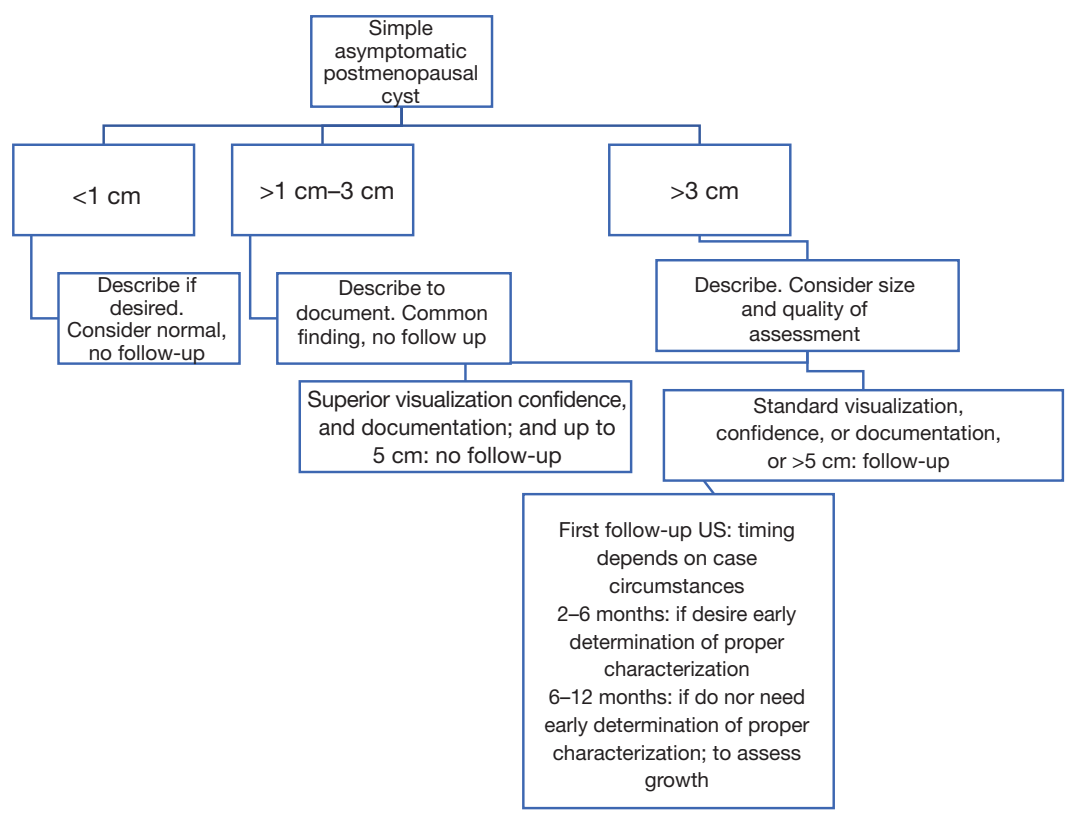

Figure 6 Flowchart showing recommendations for simple cyst management in postmenopausal women according to the SRU 2019 management in postmenopausal women according to the SRU 2019 consensus. 


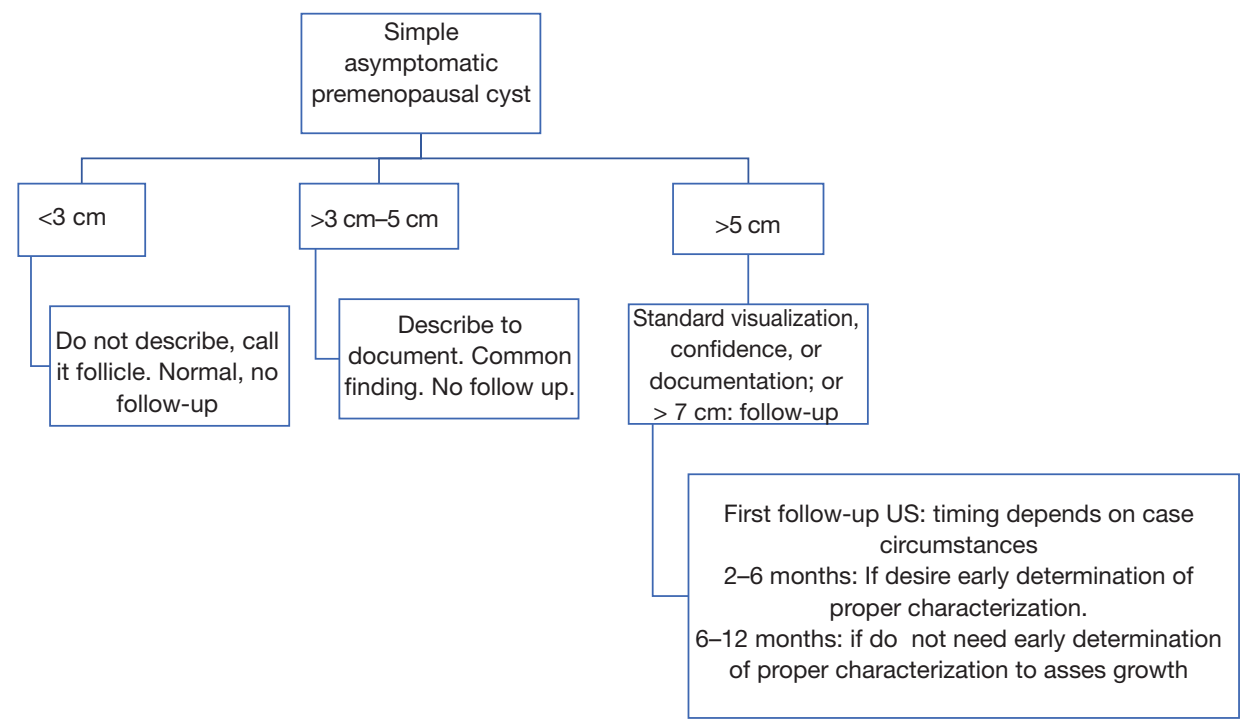

Figure 7 Flowchart showing recommendations for simple cyst management in premenopausal women according to the SRU 2019 consensus.

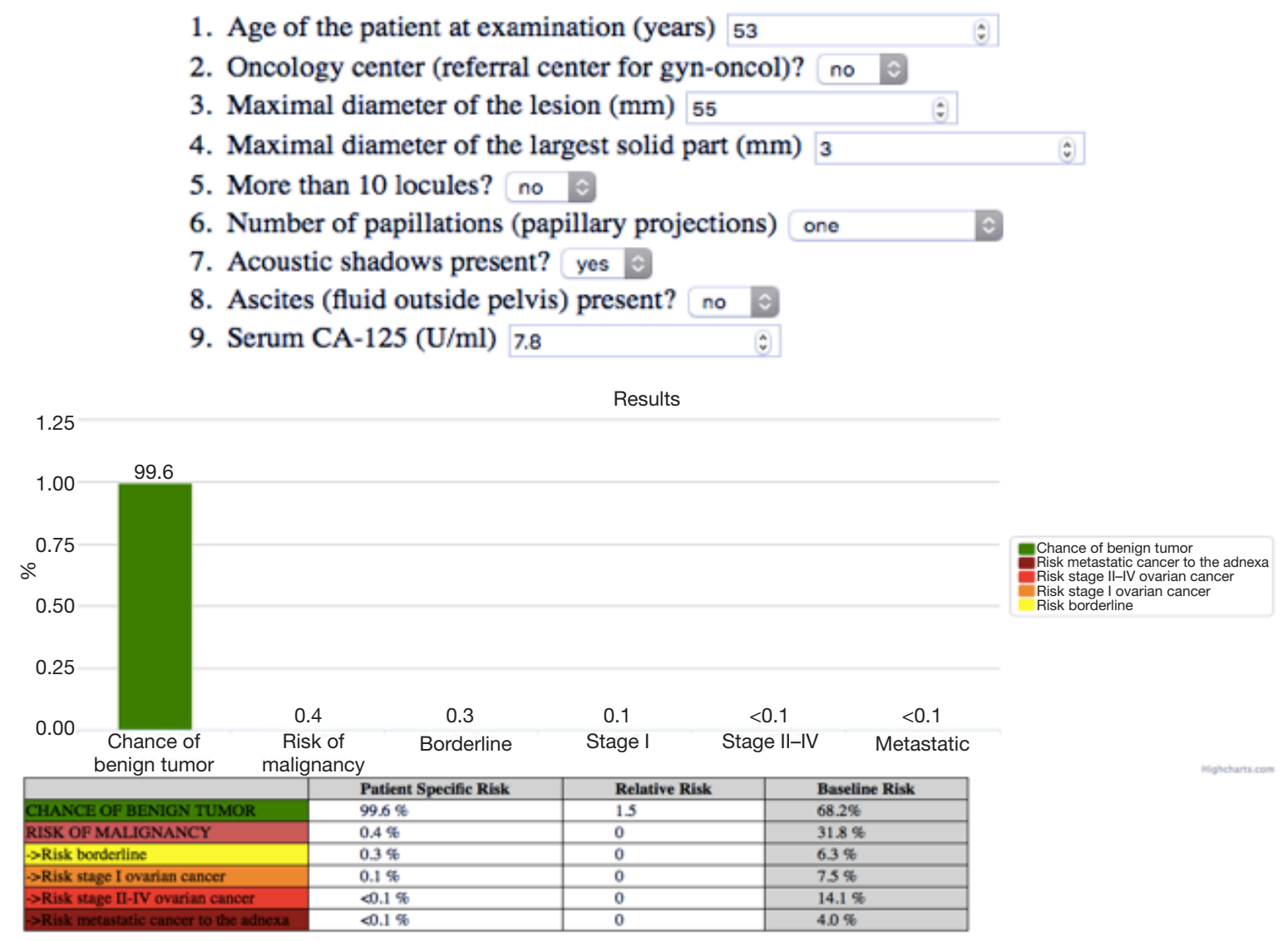

Figure 8 An example of the mathematical risk prediction IOTA-ADNEX model, showing the average risk of malignancy or benignity of an ovarian tumor, based in clinical and ultrasound criteria. Taken from: www.iotagroup.org/sites/default/files/adnexmodel 


\begin{tabular}{|c|c|c|c|c|c|}
\hline \multirow{2}{*}{$\begin{array}{l}\text { O-RADS } \\
\text { score }\end{array}$} & \multirow{2}{*}{$\begin{array}{l}\text { Risk category (IOTA } \\
\text { model) }\end{array}$} & \multirow{2}{*}{\multicolumn{2}{|c|}{$\begin{array}{l}\text { Lexicon descriptors } \\
\text { Pre-menopausal }\end{array}$}} & \multicolumn{2}{|l|}{ Management } \\
\hline & & & & \multicolumn{2}{|l|}{ Post-menopausal } \\
\hline 0 & Incomplete evaluation & \multicolumn{2}{|l|}{ N/A } & \multicolumn{2}{|c|}{ Repeat study or alternate study } \\
\hline \multirow[t]{2}{*}{1} & \multirow[t]{2}{*}{ Normal ovary } & \multicolumn{2}{|c|}{ Follicle: simple cyst up to $3 \mathrm{~cm}$} & \multirow[t]{2}{*}{ None } & \multirow[t]{2}{*}{ N/A } \\
\hline & & \multicolumn{2}{|c|}{ Corpus luteum up to $3 \mathrm{~cm}$} & & \\
\hline \multirow[t]{6}{*}{2} & \multirow{6}{*}{$\begin{array}{l}\text { Almost certainly } \\
\text { benign }(<1 \%)\end{array}$} & \multirow[t]{3}{*}{ Simple cyst } & Up to $3 \mathrm{~cm}$ & N/A & None \\
\hline & & & $>3-5 \mathrm{~cm}$ & None & \multirow[t]{2}{*}{ Follow-up in 1 year" } \\
\hline & & & $>5$ but $<10 \mathrm{~cm}$ & Follow-up in 8-12 weeks & \\
\hline & & $\begin{array}{l}\text { Classic benign } \\
\text { lesions }\end{array}$ & $\begin{array}{l}\text { Typical: hemorrhagic cyst } \\
\text { Dermoid cysts }(<10 \mathrm{~cm}) \\
\text { Endometrioma }(<10 \mathrm{~cm}) \\
\text { Paraovarian cyst (any size) peritoneal } \\
\text { inclusion cyst and hydrosalpinx (any size) }\end{array}$ & \multicolumn{2}{|c|}{$\begin{array}{l}\text { Individual management (to more information see: } \\
\text { O-RADS US risk stratification and management } \\
\text { system for classic benign lesions and associated } \\
\text { descriptors by the ACR }\end{array}$} \\
\hline & & \multirow{2}{*}{$\begin{array}{l}\text { Non-simple } \\
\text { unilocular cysts, } \\
\text { smooth inner } \\
\text { margin }\end{array}$} & Up to $3 \mathrm{~cm}$ & None & $\begin{array}{l}\text { Follow-up in } 1 \text { year } \\
\text { if concerning, US } \\
\text { specialist or MRI }\end{array}$ \\
\hline & & & $>3$ but $<10 \mathrm{~cm}$ & $\begin{array}{l}\text { Follow-up in 8-12 weeks if } \\
\text { concerning, US specialist }\end{array}$ & US specialist or MRI \\
\hline \multicolumn{6}{|l|}{ B } \\
\hline \multirow[t]{4}{*}{3} & \multirow{4}{*}{$\begin{array}{l}\text { Low risk of } \\
\text { malignancy } \\
(1 \% \text { to }<10 \%)\end{array}$} & \multicolumn{3}{|c|}{ Typical dermoid cyst, endometriomas, hemorrhagic cysts $>10 \mathrm{~cm}$} & \multirow{4}{*}{$\begin{array}{l}\text { US specialist or MRI } \\
\text { management by } \\
\text { gynecologist }\end{array}$} \\
\hline & & \multicolumn{3}{|c|}{ Unilocular cyst any size, with irregular inner wall $<3 \mathrm{~mm}$ height } & \\
\hline & & \multicolumn{3}{|c|}{ Multilocular cyst up to $10 \mathrm{~cm}$, smooth inner wall, $C S=1-3$} & \\
\hline & & \multicolumn{3}{|c|}{ Solid smooth, any size, CS=1 } & \\
\hline \multirow[t]{6}{*}{4} & \multirow{6}{*}{$\begin{array}{l}\text { Intermediate risk } \\
(10 \% \text { to }<50 \%)\end{array}$} & \multirow{3}{*}{$\begin{array}{l}\text { Multilocular cyst, no } \\
\text { solid component }\end{array}$} & \multicolumn{2}{|l|}{ Up to $10 \mathrm{~cm}$, smooth inner wall, $\mathrm{CS}=1-3$} & \multirow{6}{*}{$\begin{array}{l}\text { US specialist or MRI } \\
\text { Management } \\
\text { by gynecologist } \\
\text { with gynecology } \\
\text { oncologist } \\
\text { consultation or } \\
\text { solely by gynecology } \\
\text { oncologist }\end{array}$} \\
\hline & & & \multicolumn{2}{|l|}{ Any size, smoot inner wall, $C S=4$} & \\
\hline & & & $\begin{array}{l}\text { Any size, irregular inner wall and/or irregu } \\
\text { score }\end{array}$ & Alar Septations, any color & \\
\hline & & $\begin{array}{l}\text { Unilocular cyst with } \\
\text { solid component }\end{array}$ & Any size, $0-3$ papillary projections, $C S=a$ & & \\
\hline & & $\begin{array}{l}\text { Multilocular cyst with } \\
\text { solid component }\end{array}$ & Any size, $C S=1-2$ & & \\
\hline & & Solid & Smooth, any size, $C S=2-3$ & & \\
\hline 5 & High risk (>50\%) & Uniocular cyst, any si & ze, equal or $>4$ papillary projections, $C S=a$ & & Gynecology \\
\hline & & Multilocular cyst with & solid component, any size, $C S=3-4$ & & \\
\hline & & Solid smooth. Any siz & e $C S=4$ & & \\
\hline & & Solid Irregular, any siz & e, CS=any & & \\
\hline & & Ascites and/or peritor & eal nodules ${ }^{\S}$ & & \\
\hline
\end{tabular}

Figure 9 O-RADS US risk stratification and management system. "Il, at a minimum, at least 1-year follow-up showing stability or decrease in size is recommended with consideration of annual follow-up of up to 5 years, if stable. However, there is currently a paucity of evidence for defining optimal duration or interval of timing for surveillance. ${ }^{\S}$, presence of ascites with category 1-2 lesion, must consider other malignant or nonmalignant etiologies of ascites. CS, color score; GYN, gynecologic; IOTA, International Ovarian Tumor Analysis; N/A, not applicable. Adapted, from the American College of Radiology (11). 
malignancy). Includes most of the unilocular cysts smaller than $10 \mathrm{~cm}$. Comprises: simple cysts, nonsimple unilocular cyst with smooth walls and cysts that may be described by using "classic benign descriptors", which are the following: typical hemorrhagic cyst, dermoid cysts, endometrioma, paraovarian cyst, peritoneal inclusion cyst and hydrosalpinx.

- RADS 3: low risk of malignancy ( $1 \%$ to $<10 \%)$. In this group, the color score becomes incorporated into the risk stratification system.

* RADS 4: lesions with an intermediate risk of malignancy $(10 \%$ to $<50 \%)$. Need ultrasound specialist review or MRI as well as management by a gynecologist with gynecology oncologist support or solely by a gynecology oncologist.

* RADS 5: lesions with a high risk of malignancy $(\geq 50 \%)$ Needs a referral to gynecology oncologist. This category, includes descriptors with high predictive value of malignancy, the presence of ascites or peritoneal nodules.

\section{$M R$ protocol for adnexal mass characterization}

Various MR protocols have been used to evaluated ovarian lesion.

T1 weighted $(\mathrm{T} 1 \mathrm{~W})$ images in axial plane without and with fat saturation. These are used to identify macroscopic fat and hemorrhage. T1W chemical shift imaging using dual in phase and opposed phase gradient echo (GRE) sequences in axial plane. This are used to confirm lipid and macroscopic fat (23).

T2 weighted (T2W) images in axial sagittal and coronal planes without fat saturation, for optimizing tissue characterization (23).

T1W contrast enhanced images using gadolinium are used to evaluate vascularity of soft tissues. In ovarian lesions it is important to recognize papillary projections, masses and nodules, or thick septations. Postcontrast imaging protocols include fat saturated multiphase imaging acquisitions during arterial and venous phases, and one or more delayed phases. Pre-contrast and post-contrast imaging should be performed with the coverage and scan parameters to enable imagen subtraction. Short acquisitions of 15 seconds repeated over a period of 3 to 4 should be done with acquisitions at 30, 90, 120 and 150 seconds (24).

It is also important to obtain diffusion weighted imaging (DWI) done at both low and high b values $>$ b800 (25).
Contrast-enhanced MR is recommended for all indeterminate adnexal masses. This technique evaluates the leakage of contrast from capillaries into the extravascular extracellular space. These findings can be analyzed through three different approaches: descriptive, semi-quantitative and quantitative $(26,27)$. A study performed by Mansour et al. used dynamic imaging parameters where they included kinetic curve analysis. Three patterns of plotted slope enhancement ratio curves were described: (I) continuous rise, (II) plateau and (III) early washout. The type I was detected in $35.3 \%$; of these $68 \%$ proved benign, $15 \%$ had a low malignant potential and $17 \%$ were malignant with an invasive component. Type II was demonstrated in $24 \%$ of the cases. $16.7 \%$ were benign, borderline masses accounted for $22.2 \%$ and malignant masses were proved on $61 \%$ of the cases. Type III was found in $40.7 \%$ of the cases; $16.4 \%$ for borderline tumors and $83.6 \%$ for malignant ovarian masses (28).

\section{ADNEX MR scoring system}

MR has the best potential for preoperative evaluation of adnexal masses. Thomassin-Naggara et al. published the MR scoring system in 2013 with a sensitivity of $93.5 \%$ and specificity of $96.6 \%$ in the detection of malignant adnexal mases (26). Adnex MR scoring system (Table 6) may potentially influence pelvic mass management, inspired by the BIRADS classification this imaging scoring system accurately relays the radiologist's suspicions to the clinician. The combination or the morphologic and functional MR imaging features helps predict the final diagnosis. This scoring system would help to standardize MR imaging reporting with the aim of improving patient care $(26,27)$. Criteria for considered predictive of benignity purely cystic lesions, a regular and homogeneous solid component with low signal intensity it T2W and solid component with a type 1-time signal intensity curve. The following criteria predictive of malignancy: vegetations, an irregular or heterogeneous solid component with high signal intensity on DW, a solid component with a type 3-time signal intensity curve or peritoneal implants or abdominal or pelvic ascites (Tables 6-8, Figures 10-14) $(1,24,26,27,29,30)$.

\section{$O-R A D S$}

This committee was created in order to standardize lexicon that would allow the development of a practical and uniform vocabulary to describe the imaging characteristics 
Table 6 ADNEX MR scoring system (29)

\begin{tabular}{lll}
\hline 1 & No ovarian mass & No mass \\
\hline 2 & Benign mass & Unilocular cystic mass of any type: no wall enhancement \\
& & Unilocular simple cyst with no solid tissue with or without wall enhancement \\
& Endometroid or fatty masses without solid tissue with or without wall enhancement \\
& & $\begin{array}{l}\text { Cyst with solid tissue: homogeneous low signal on diffusion or T2W within solid tissue with mild or } \\
\text { moderate enhancement (curves type 1 or 2) }\end{array}$ \\
& $\begin{array}{l}\text { Probably benign } \\
\text { mass }\end{array}$ & $\begin{array}{l}\text { Unilocular proteinaceous or hemorrhagic cyst with wall enhancement without solid tissue } \\
\text { Cysts with solid tissue with intermediate T2 signal and type 1 enhancement curves }\end{array}$ \\
& $\begin{array}{l}\text { Indeterminate mass } \\
\text { Probably malignant } \\
\text { mass }\end{array}$ & $\begin{array}{l}\text { Cysts with solid tissue, type 2 time signal intensity curve, intermediate T2 signal and high intensity on DWI } \\
\text { and high intensity in DWI }\end{array}$ \\
\hline
\end{tabular}

Table 7 ADNEx MR Lexicon (part 1) $(24,27,30)$

\begin{tabular}{ll}
\hline Finding & Description \\
\hline Purely cystic mass & $\begin{array}{l}\text { Unilocular cyst or hydrosalpinx, both of which have low T1-weighted and high T2-weighted MR signal intensities, } \\
\text { and no internal enhancement }\end{array}$ \\
$\begin{array}{l}\text { Purely } \\
\text { endometriotic mass }\end{array}$ & $\begin{array}{l}\text { Lesion displaying high T1-weighted signal intensity greater than or equal to that of subcutaneous fat, with shading } \\
\text { on T2-weighted MR images and no internal enhancement }\end{array}$ \\
Purely fatty mass & $\begin{array}{l}\text { Lesion displaying high T1-weighted signal intensity that disappeared after fat saturation and displaying no solid } \\
\text { tissue }\end{array}$ \\
Wall enhancement & $\begin{array}{l}\text { Wall enhancement of the wall of a cyst } \\
\text { Bi- or multilocularity }\end{array}$ \\
& $\begin{array}{l}\text { The presence of two or more septa in a cyst (a septum is defined as a thin strand of tissue running across the cyst } \\
\text { cavity from one internal surface to the contralateral side) }\end{array}$ \\
Grouped septa & $\begin{array}{l}\text { The presence of three or more septa close together in a part of the cyst; thickened regular septum or septa: a } \\
\text { smooth septation with a thickness } \geq 3 \text { mm within a cystic tissue }\end{array}$ \\
Solid tissue & $\begin{array}{l}\text { As defined by the IOTA group, solid tissue shows flow at Doppler US flow. Thus, at MR imaging, solid tissue } \\
\text { enhances after gadolinium chelate injection. In adnexal tumors, according to the IOTA group (13), diffuse wall } \\
\text { thickening, normal ovarian stroma, and regular septa are not considered to represent solid tissue. Thus, solid tissue } \\
\text { is either thickened irregular septa, and/or vegetation, and/or a solid portion (including completely solid mass) }\end{array}$ \\
\hline
\end{tabular}


Table 8 ADNEx MR Lexicon (part 2) (24,27,30)

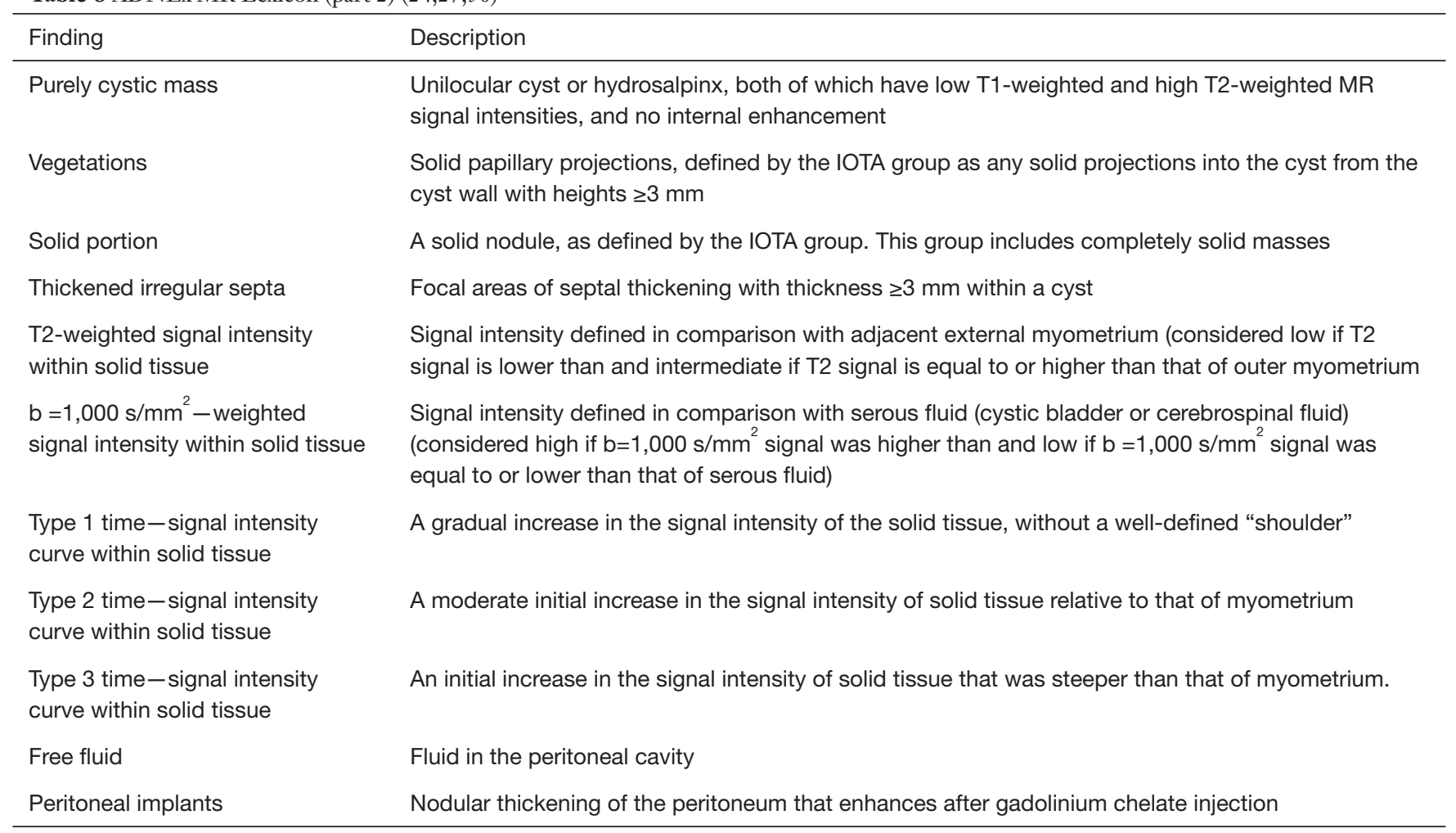

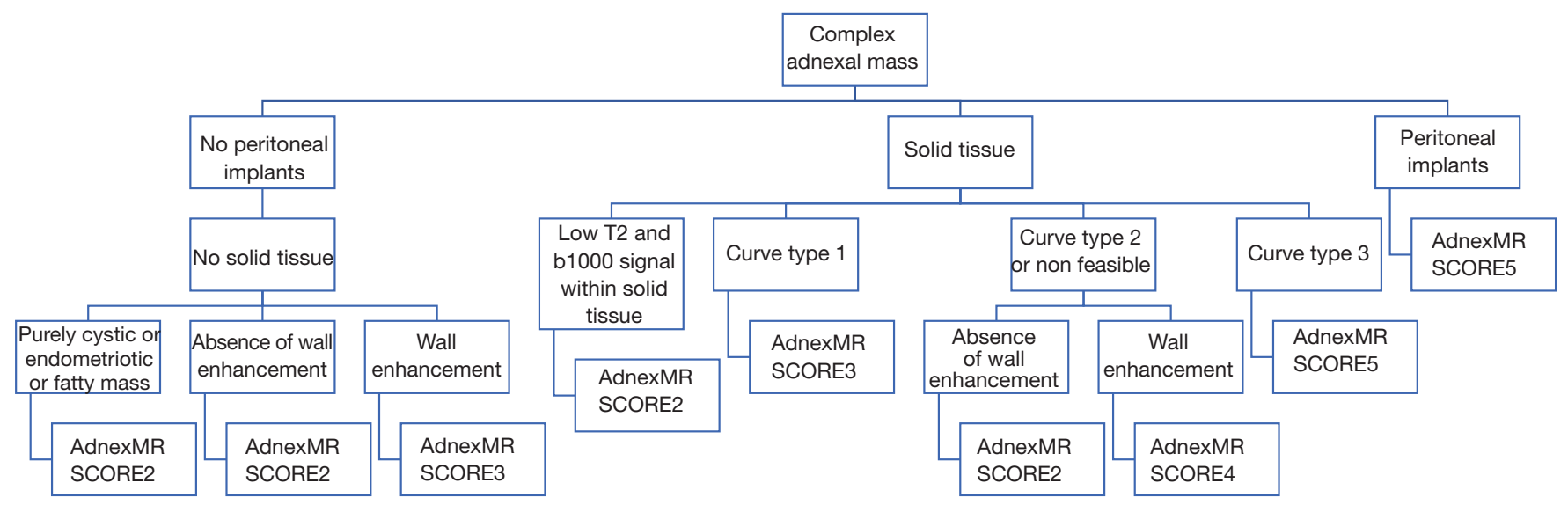

Figure 10 ADNEx MR Scoring System Flowchart showing recommendations for assessment adnexal masses. 

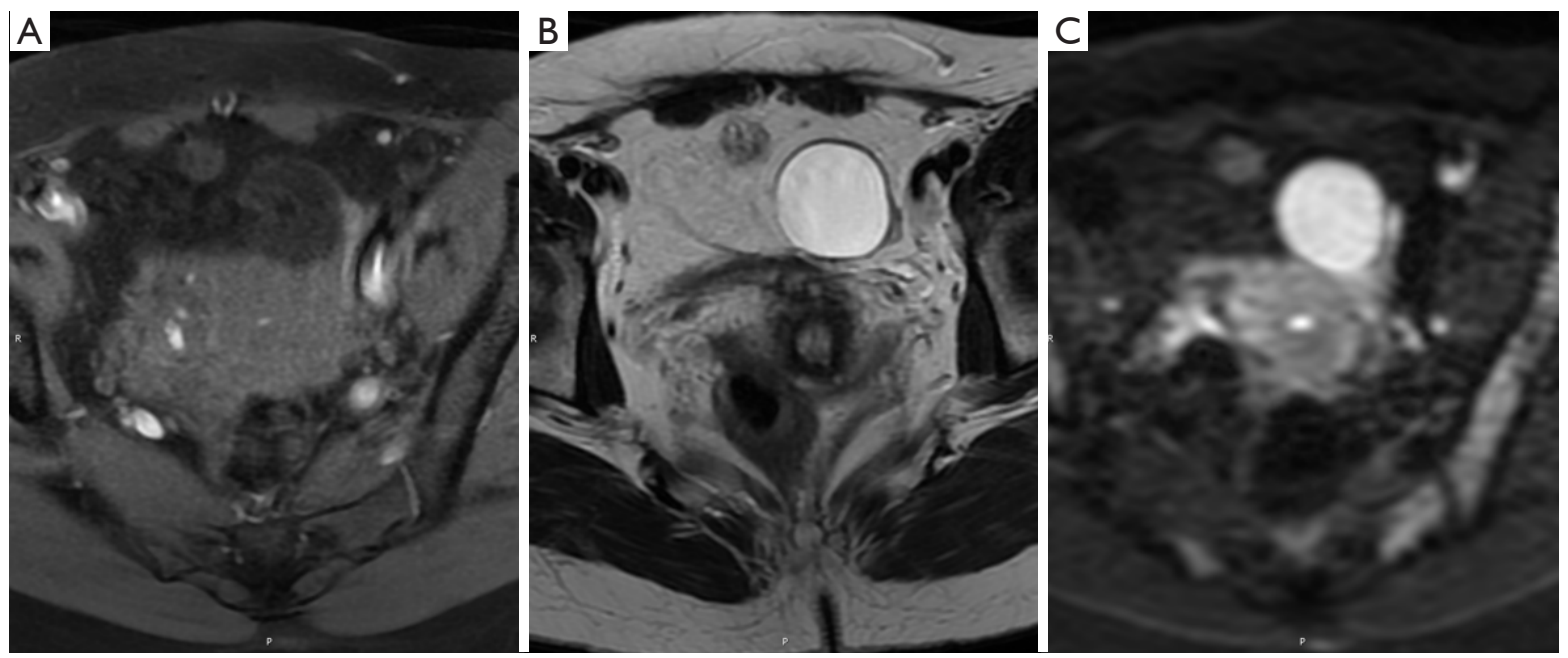

Figure 11 MRI of a female patient with a simple unilocular cyst ADNEx Score 2. (A) Axial T1W1 + C showing a low signal left ovarian mass; (B) axial T2WI MR demonstrates high intensity in the same mass; (C) axial DWI showing high intensity within the lesion.
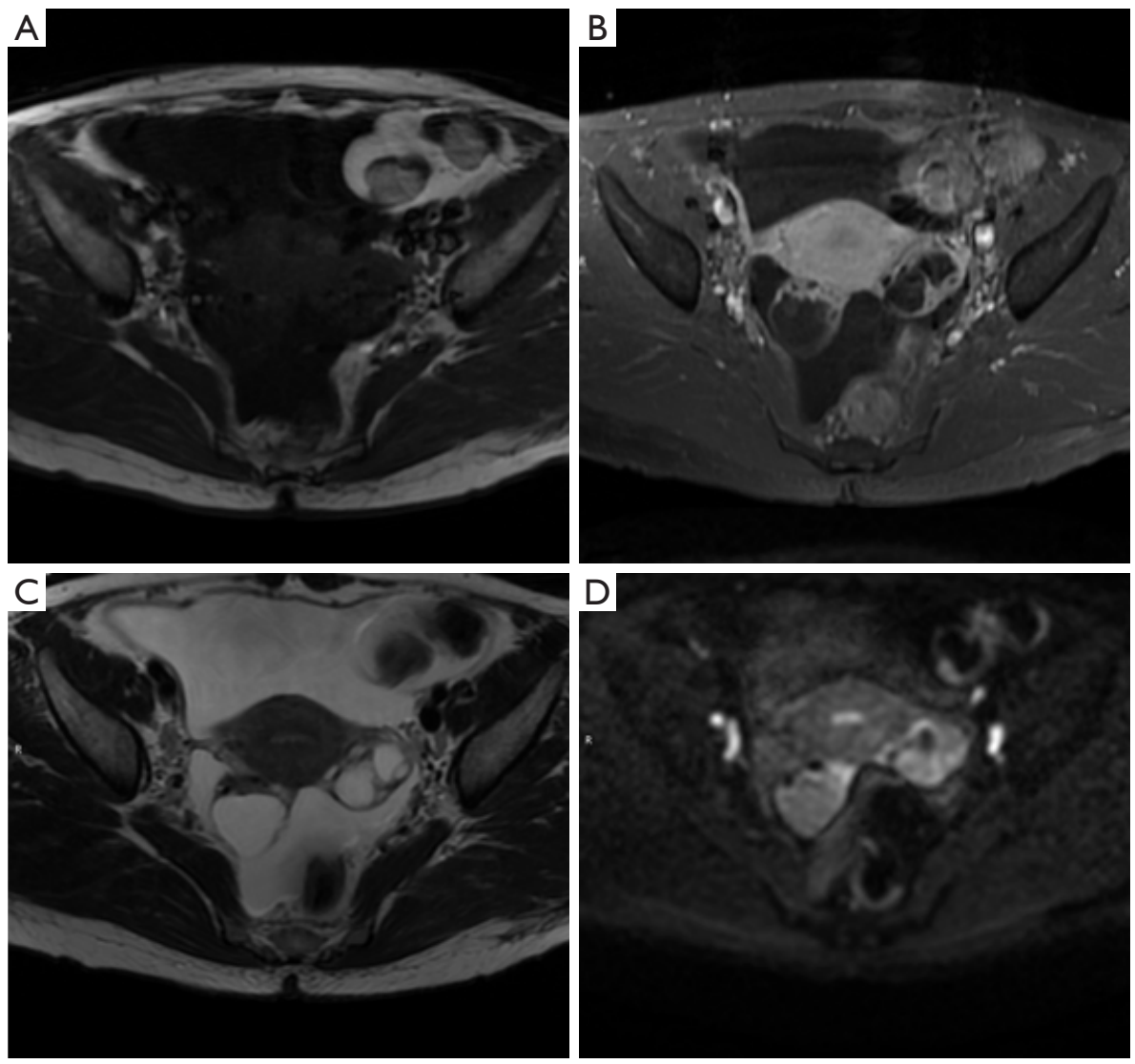

Figure 12 Multilocular cyst without solid tissue ADNEx Score 2. (A) Axial T1 shows bilateral adnexal well-defined masses with multiple locules; (B) T1WI + C show no enhancement in both lesions; (C) T2WI demonstrates both cysts with multiple high intensity lesions; (D) axial DWI shows high intensity in bilateral cysts. 

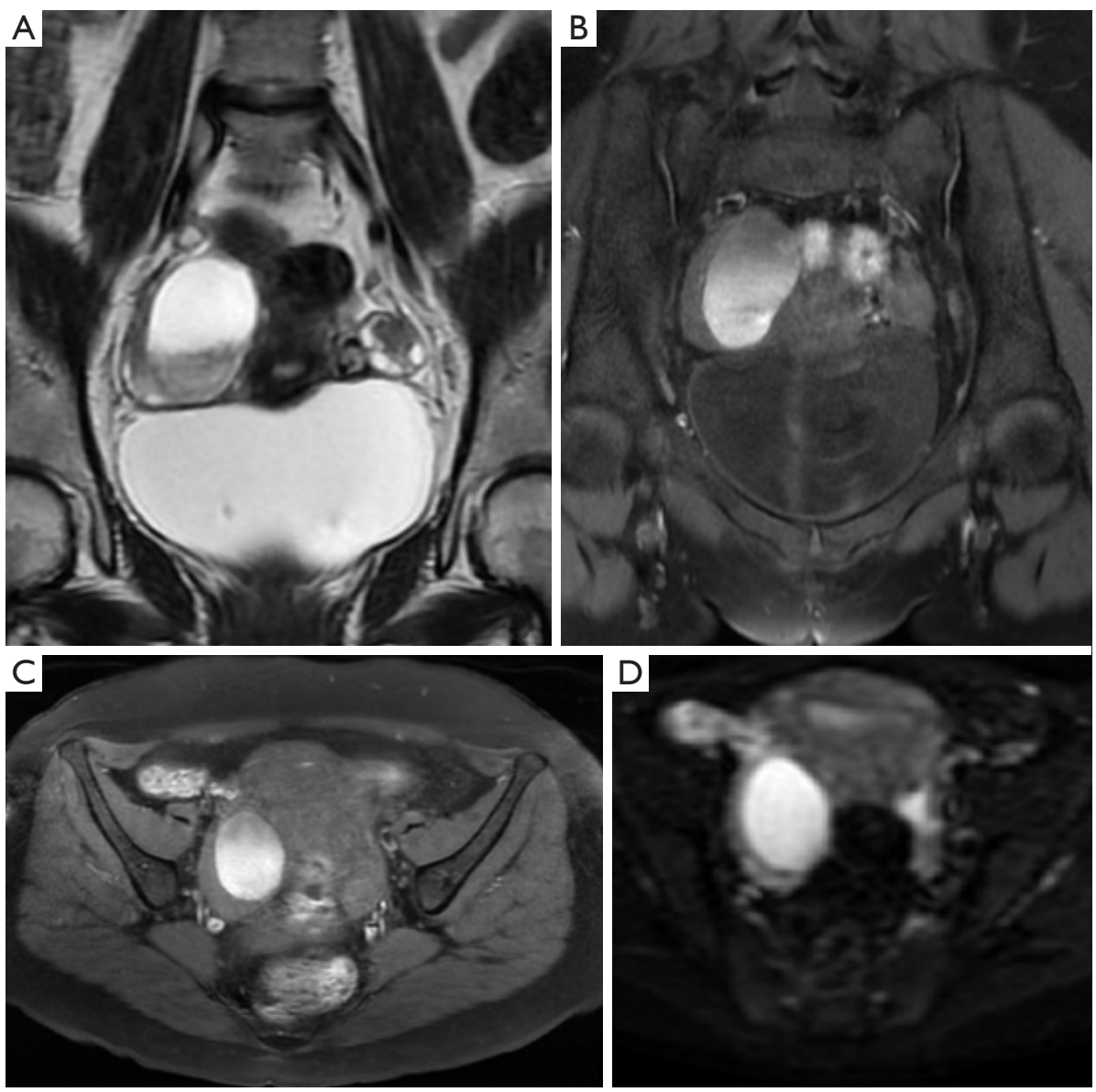

Figure $13 \mathrm{MRI}$ of a female patient with a right hemorrhagic cyst. ADNEx Score 3 (A) coronal T2W1 showing a right adnexal cystic mass with hemorrhagic component and a fluid-fluid level (B). (C) Coronal and axial T1FS shows high signal intensity within the mass (D) DWI demonstrate high signal intensity $(1,26)$.

of ovarian masses. From category O-RADS 3 low risk of malignancy $(1 \%$ to $<10 \%)$ needs a referral to ultrasound specialist or gynecologist with a view to MR and O-RADS 4 lesions with an intermediate risk of malignancy (10\% to $<50 \%$ ) needs ultrasound specialist review or MR as well as management by a gynecologist. MR becomes a complement to the approach of patients with these categories (30).

\section{CT and PET/CT imaging}

Although the majority of incidental findings in computed tomography are benign there can be indeterminate or suspicious findings on. A CT examination $(29,31)$.

Five percent of all CT scans may have adnexal cysts, which are mostly physiologic in premenopausal women or simple adnexal cysts in postmenopausal women.
The current American College of Radiology (8) Recommendations in regard to incidental adnexal findings represent a guideline that is based on the radiologist experience and the results of previous studies.

Boos et al. evaluated a prevalence of adnexal cysts initially detected at $\mathrm{CT}$ in $6.6 \%$ of the patients. Among all the patients, a $0.7 \%$ (18 cases) of a given diagnosis of ovarian cancer and $6.5 \%$ (7 cases) were large cysts. It is unlikely that simple cysts represent cancer and therefore imaging follow up criteria with other modalities besides ultrasound are not recommended.

A completely different scenario would be in hyperdense ovarian cysts as there are mucinous tumors and endometriomas that can manifest as hyperattenuating cysts. Therefore, follow-up imaging makes sense in agreement with the current ACR guidelines, no matter patient's age or 

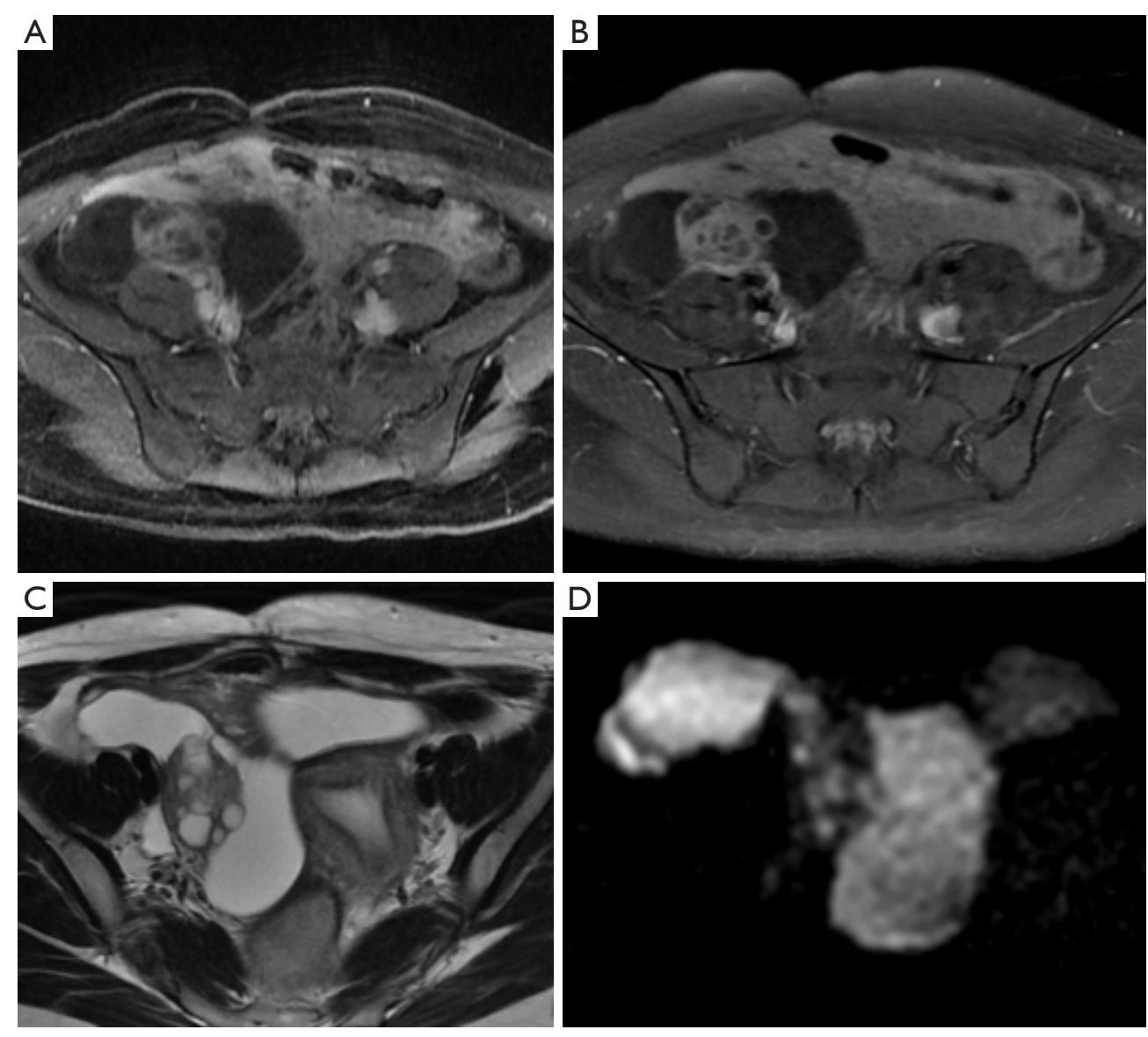

Figure 14 MRI of a female patient with a right multilocular cyst with solid tissue. ADNEx Score 4 (A) T1W1 showing a right adnexal cystic mass with a solid component; (B) T1WI FS shows no fat within the lesion; (C) T2W1 shows intermediate signal in solid tissue; (D) axial DWI demonstrates high signal in the right ovary.

menopausal status $(32,33)$ (Figure 15).

PET/CT imaging with fluorine 18 fluorodeoxyglucose in the initial evaluation of patients with ovarian cancer is limited especially in those with early stage disease and in characterizing adnexal masses. Many ovarian lesions can have FDG uptake such as physiologic changes, teratomas, endometriomas, inflammatory masses, among others. FDG is mainly used as a staging tool and for the assessment of recurrent ovarian cancer (Figure 16).

\section{Conclusions}

The survival for a patient can be significantly improved with early detection. Ultrasound is a good low-cost imaging modality, of easy availability but can be subjective in comparison with other modalities. That is the reason why IOTA and O-RADS can help to improve that, as they are easy and reproducible classification systems with high sensibility and specificity for predicting ovarian malignancies. Other imaging modalities like CT imaging and PET/CT imaging remains as great imaging tools for cancer stratification. Cystic adnexal masses are a frequent incidental finding with a very low prevalence of malignancy. Hyperdense lesions should have follow-up images with adnexal ultrasound. 

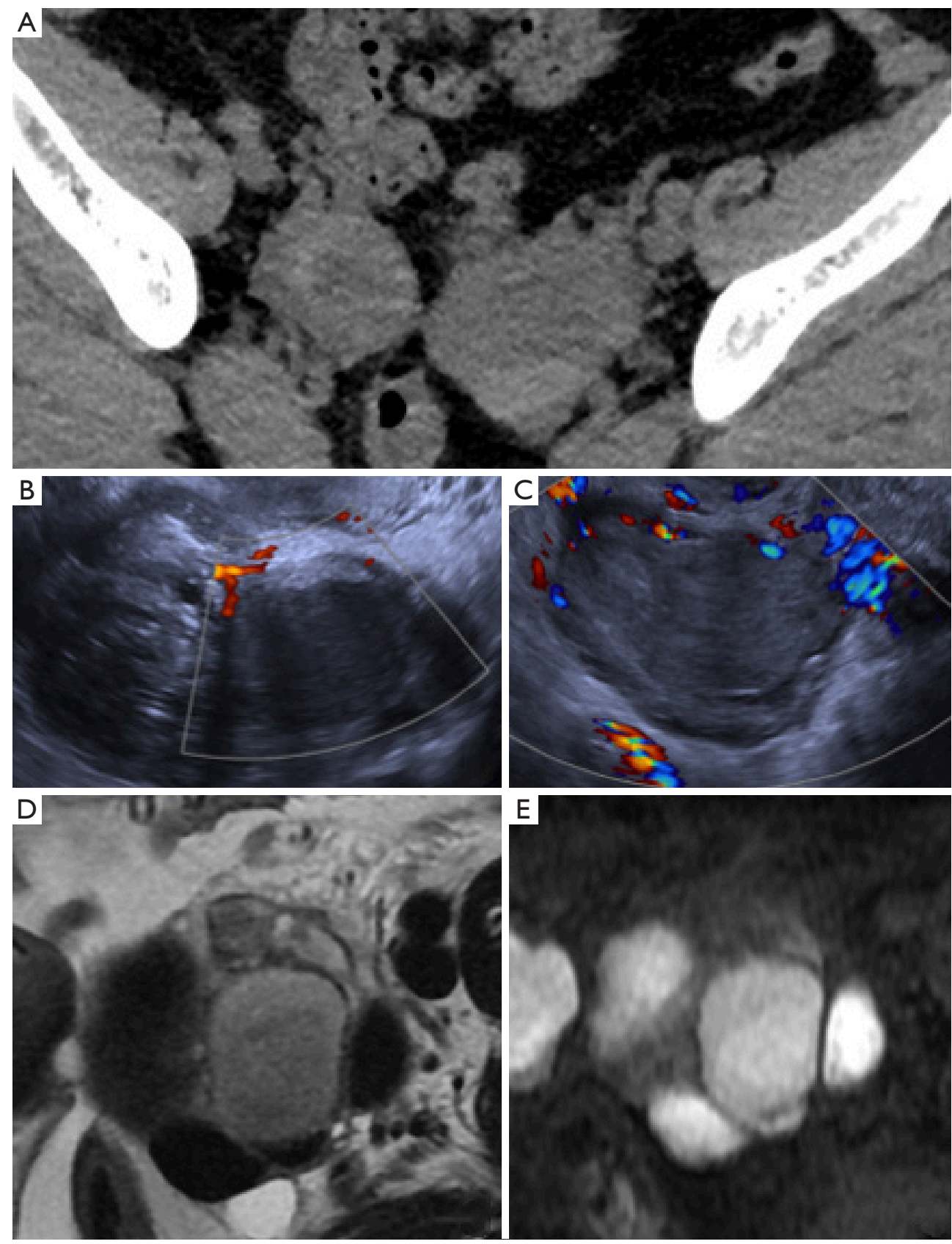

Figure 15 Incidental adnexal cyst (A) Simple CT showing hyperdense adnexal masses in both ovaries; (B,C) indeterminate adnexal mass in a transvaginal ultrasound with hypoechoic (B) and isoechoic components (C) with peripheral color scale 2-3. (D) T2 weighted MRI and (E) $\mathrm{T} 1 \mathrm{FS}+\mathrm{C}$ show a hyperintense in T1, hypointense T2 cysts consistent with endometriomas. 

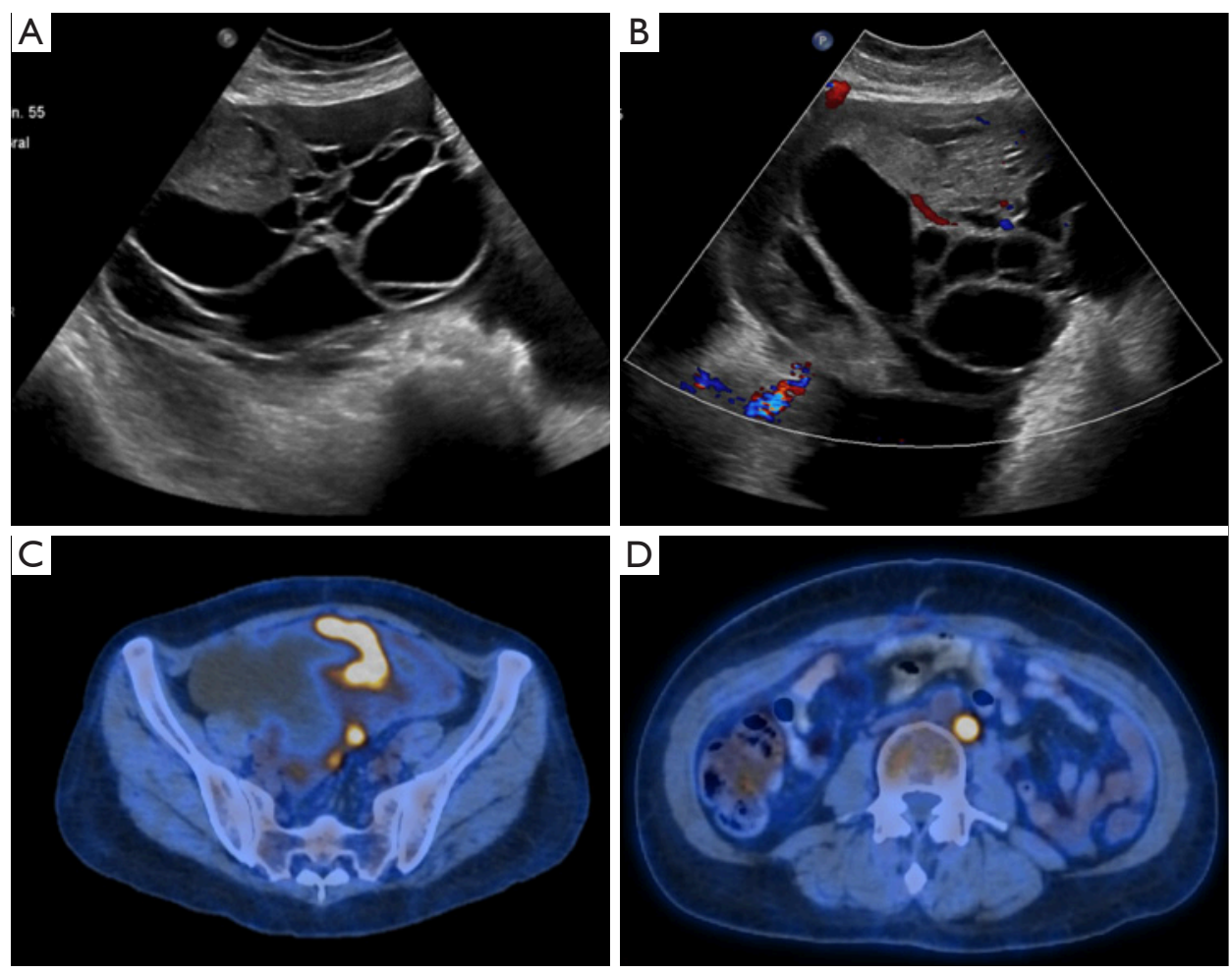

Figure $16(\mathrm{~A}, \mathrm{~B})$ Transabdominal ultrasound showing a multilocular ovarian cyst, $>10 \mathrm{~cm}$, with solid component and CS=2 at color Doppler. (C,D) PET/CT of the same ovarian lesion, showing hypermetabolism in the solid portions and a para-aortic adenopathy. Findings corresponding to a category O-RADS 4.

\section{Acknowledgments}

Funding: None.

\section{Footnote}

Provenance and Peer Review: This article was commissioned by the Guest Editor (Heriberto Medina-Franco) for the series "Ovarian Cancer" published in Chinese Clinical Oncology. The article was sent for external peer review organized by the Guest Editor and the editorial office.

Conflicts of Interest: The authors have completed the ICMJE uniform disclosure form (available at http://dx.doi. org/10.21037/cco-20-37). The series "Ovarian Cancer" was commissioned by the editorial office without any funding or sponsorship. The authors have no other conflicts of interest to declare.

Ethical Statement: The authors are accountable for all aspects of the work in ensuring that questions related to the accuracy or integrity of any part of the work are appropriately investigated and resolved.

Open Access Statement: This is an Open Access article distributed in accordance with the Creative Commons Attribution-NonCommercial-NoDerivs 4.0 International License (CC BY-NC-ND 4.0), which permits the noncommercial replication and distribution of the article with the strict proviso that no changes or edits are made and the original work is properly cited (including links to both the formal publication through the relevant DOI and the license). See: https://creativecommons.org/licenses/by-nc-nd/4.0/.

\section{References}

1. Andreotti RF, Timmerman D, Strachowski LM, et al. O-RADS US Risk Stratification and Management System: A Consensus Guideline from the ACR Ovarian-Adnexal Reporting and Data System Committee. Radiology 2020;294:168-85.

2. Torre LA, Trabert B, DeSantis CE, et al. Ovarian cancer 
statistics, 2018. CA Cancer J Clin 2018;68:284-96.

3. Mohaghegh P, Rockall AG. Imaging strategy for early ovarian cancer: characterization of adnexal masses with conventional and advanced imaging techniques. Radiographics 2012;32:1751-73.

4. Hack K, Glanc P. The Abnormal Ovary: Evolving Concepts in Diagnosis and Management. Obstet Gynecol Clin North Am 2019;46:607-24.

5. Bray F, Ferlay J, Soerjomataram I, et al. Global cancer statistics 2018: GLOBOCAN estimates of incidence and mortality worldwide for 36 cancers in 185 countries. CA Cancer J Clin 2018;68:394-424.

6. Kaijser J, Bourne T, Valentin L, et al. Improving strategies for diagnosing ovarian cancer: a summary of the International Ovarian Tumor Analysis (IOTA) studies. Ultrasound Obstet Gynecol 2013;41:9-20.

7. Basha MAA, Refaat R, Ibrahim SA, et al. Gynecology Imaging Reporting and Data System (GI-RADS): diagnostic performance and inter-reviewer agreement. Eur Radiol 2019;29:5981-90.

8. Sirunyan AM, Tumasyan A, Adam W, et al. Measurement of electroweak production of a $W$ boson in association with two jets in proton-proton collisions at $s=13$ Te. Eur Phys J C Part Fields 2020;80:43.

9. Expert Panel on Women's Imaging, Atri M, Alabousi A, et al. ACR Appropriateness Criteria ${ }^{\circledR}$ Clinically Suspected Adnexal Mass, No Acute Symptoms. J Am Coll Radiol 2019;16:S77-93.

10. Chen VW, Ruiz B, Killeen JL, et al. Pathology and classification of ovarian tumors. Cancer 2003;97:2631-42.

11. DePriest PD, Shenson D, Fried A, et al. A morphology index based on sonographic findings in ovarian cancer. Gynecol Oncol 1993;51:7-11.

12. Timmerman D, Valentin L, Bourne TH, et al. Terms, definitions and measurements to describe the sonographic features of adnexal tumors: a consensus opinion from the International Ovarian Tumor Analysis (IOTA) Group. Ultrasound Obstet Gynecol 2000;16:500-5.

13. Froyman W, Timmerman D. Methods of Assessing Ovarian Masses: International Ovarian Tumor Analysis Approach. Obstet Gynecol Clin North Am 2019;46:625-41.

14. Patel-Lippmann KK, Sadowski EA, Robbins JB, et al. Comparison of International Ovarian Tumor Analysis Simple Rules to Society of Radiologists in Ultrasound Guidelines for Detection of Malignancy in Adnexal Cysts. AJR Am J Roentgenol 2020;214:694-700.

15. Jeong YY, Outwater EK, Kang HK. Imaging evaluation of ovarian masses. Radiographics 2000;20:1445-70.
16. Mahadevan K, Sruthi S, Sridevi S, et al. Fourth Dimension in Reconstruction of Defects Following Excision of Basal Cell Carcinoma of Head and Neck!. J Cutan Aesthet Surg 2018;11:110-9.

17. Givens V, Mitchell GE, Harraway-Smith C, et al. Diagnosis and management of adnexal masses. Am Fam Physician 2009;80:815-20.

18. Kaijser J, Bourne T, De Rijdt S, et al. Key findings from the International Ovarian Tumor Analysis (IOTA) study: an approach to the optimal ultrasound based characterisation of adnexal pathology. Australas J Ultrasound Med 2012;15:82-6.

19. Hidalgo JJ, Ros F, Aubá M, et al. Prospective external validation of IOTA three-step strategy for characterizing and classifying adnexal masses and retrospective assessment of alternative two-step strategy using simple-rules risk. Ultrasound Obstet Gynecol 2019;53:693-700.

20. Garg S, Kaur A, Mohi JK, et al. Evaluation of IOTA Simple Ultrasound Rules to Distinguish Benign and Malignant Ovarian Tumours. J Clin Diagn Res 2017;11:TC06-9.

21. Timmerman D, Testa AC, Bourne T, et al. Simple ultrasound-based rules for the diagnosis of ovarian cancer. Ultrasound Obstet Gynecol 2008;31:681-90.

22. Levine D, Patel MD, Suh-Burgmann EJ, et al. Simple Adnexal Cysts: SRU Consensus Conference Update on Follow-up and Reporting. Radiology 2019;293:359-71.

23. Stein EB, Wasnik AP, Sciallis AP, et al. MR ImagingPathologic Correlation in Ovarian Cancer. Magn Reson Imaging Clin N Am 2017;25:545-62.

24. Pereira PN, Sarian LO, Yoshida A, et al. Accuracy of the ADNEX MR scoring system based on a simplified MRI protocol for the assessment of adnexal masses. Diagn Interv Radiol 2018;24:63-71.

25. Gity M, Parviz S, Saligheh Rad H, et al. Differentiation of Benign from Malignant Adnexal Masses by Dynamic Contrast-Enhanced MRI (DCE-MRI): Quantitative and Semi-quantitative analysis at 3-Tesla MRI. Asian Pac J Cancer Prev 2019;20:1073-9.

26. Thomassin-Naggara I, Aubert E, Rockall A, et al. Adnexal masses: development and preliminary validation of an MR imaging scoring system. Radiology 2013;267:432-43.

27. Thomassin-Naggara I, Toussaint I, Perrot N, et al. Characterization of complex adnexal masses: value of adding perfusion- and diffusion-weighted MR imaging to conventional MR imaging. Radiology 2011;258:793-803.

28. Mansour SM, Saraya S, El-Faissal Y. Semi-quantitative contrast-enhanced MR analysis of indeterminate 
ovarian tumours: when to say malignancy?. Br J Radiol 2015;88:20150099.

29. Sadowski EA, Robbins JB, Rockall AG, et al. A systematic approach to adnexal masses discovered on ultrasound: the ADNEx MR scoring system. Abdom Radiol (NY) 2018;43:679-695.

30. Andreotti RF, Timmerman D, Benacerraf BR, et al. Ovarian-Adnexal Reporting Lexicon for Ultrasound: A White Paper of the ACR Ovarian-Adnexal Reporting and Data System Committee. J Am Coll Radiol 2018;15:1415-29.

31. Boos J, Brook OR, Fang J, et al. Ovarian Cancer:

Cite this article as: Vázquez-Manjarrez SE, Rico-Rodriguez OC, Guzman-Martinez N, Espinoza-Cruz V, Lara-Nuñez D. Imaging and diagnostic approach of the adnexal mass: what the oncologist should know. Chin Clin Oncol 2020;9(5):69. doi: 10.21037/cco-20-37
Prevalence in Incidental Simple Adnexal Cysts Initially Identified in CT Examinations of the Abdomen and Pelvis. Radiology 2018;286:196-204.

32. Levine D, Brown DL, Andreotti RF, et al. Management of asymptomatic ovarian and other adnexal cysts imaged at US: Society of Radiologists in Ultrasound Consensus Conference Statement. Radiology 2010;256:943-54.

33. Patel MD, Ascher SM, Paspulati RM, et al. Managing incidental findings on abdominal and pelvic CT and MRI, part 1: white paper of the ACR Incidental Findings Committee II on adnexal findings. J Am Coll Radiol 2013;10:675-81. 